\title{
El miedo a crecer: El síndrome de Peter Pan a través del cine
}

\author{
Natalia Torres Vilar \\ Universidad de Lima
}

Recibido: 22 de mayo del 2011 / Aprobado: 26 de junio del 2011

Peter Pan, personaje central de la novela que J. M. Barrie escribiera en 1904, fue elevado a la categoría de síndrome por el doctor Dan Kiley, quien define los conflictos de algunos adultos que no se sienten capaces de crecer. Partiendo de la observación de que Kiley presenta una minuciosa descripción del síndrome junto a una explicación superficial, el presente estudio ofrece una mirada psicoanalitica para abordar los temas que subyacen a la formación del hoy llamado síndrome de Peter Pan. A partir del análisis de la novela original de Barrie, así como de los filmes Peter Pan (2003) y Hook (1991), se discuten algunas posibles causas del síndrome, tales como el conflicto edípico observado por Freud y su elaboración lacaniana en cuanto a la no-relación sexual; y, en relación con la imagen materna, a los miedos a la sexualidad y la muerte.

\section{síndrome de Peter Pan}

The fear of growing up: The Peter Pan syndrome through films

Peter Pan, main character of the novel written by J. M. Barrie in 1904, was reconceptualized into a syndrome category by Dr. Dan Kiley, who defines this syndrome as the conflicts exhibit by some adults who do not feel capable of growing up. Kiley presents a thorough description of the syndrome though stops short of a superficial explanation. Therefore, in this the present study I present a psychoanalytic review to address the issues underlying the origins of the so-called Peter Pan Syndrome. Through the analysis of Barrie's original novel, as well as the films Peter Pan (2003) and Hook (1991), some possible causes of the syndrome are discussed, such as the Freudian oedipal complex and its Lacanian elaboration concerning the absence of a sexual relation, and in relation to the maternal image, the fear of sexuality and the fear of death.

\section{Peter Pan syndrome}

Correo electrónico: ntorres@ulima.edu.pe 
Peter Pan, personaje central de la novela que James Mathew Barrie (2006) escribiera en 1904, fue elevado a la categoría de síndrome por el doctor Dan Kiley (1983), psicólogo clínico, en su texto The Peter Pan syndrome: Men who never grow up. En este best seller Kiley define los conflictos de algunos adultos que no se sienten capaces de crecer. Un año más tarde escribió otro texto que también rompió récords de ventas en Estados Unidos, The Wendy dilemma: When women stop mothering their men (Kiley, 1984). Ambos textos desencadenaron un gran interés popular y acapararon en su momento los foros de autoayuda. La inmadurez en los hombres y su incapacidad de compromiso aparecían como las quejas recurrentes de mujeres preocupadas por sus parejas.

Los artículos publicados, incluyendo los textos de Kiley, son básicamente descriptivos, y presentan el síndrome de Peter Pan como un desorden de la personalidad que afecta principalmente a los hombres y que se caracteriza por una inmadurez psicológica en aspectos sociales y sexuales, irresponsabilidad, rebeldía, cólera, narcisismo, dependencia y manipulación. Se trata de personas que se niegan a dejar atrás la adolescencia, se resisten a adquirir las responsabilidades que conlleva la etapa madura y optan por anclarse en la comodidad de afrontar el día a día sin llegar más allá. Adicionalmente, existe una incapacidad para hacer conscientes tales dificultades, y los sujetos tienden más bien a culpar a los demás por lo que les ocurre a ellos. Particularmente, Dan Kiley (1983) lo ha descrito como el conjunto de rasgos que tiene la persona que no sabe o no puede renunciar a ser hijo para empezar a ser padre. En general, se trata de hijos que nunca se marchan de la casa paterna, que suelen socializar con grupos más jóvenes que ellos, evitando responsabilidades correspondientes a su edad cronológica.

Si bien se trata de sujetos centrados en recibir, pedir y criticar, más que en dar o hacer, resultan vibrantes, cautivadores y carismáticos y suelen ser líderes, asegurándose de tener al lado a alguien que cubra sus necesidades básicas; dicha alegría, intensidad y seguridad son máscaras que esconden su inseguridad y temor a no ser queridos, así como un gran temor a la soledad. Pueden tener éxito profesional, pero no sienten estabilidad, pues son ansiosos ante las evaluaciones de superiores y muy intolerantes a la crítica.

En un estudio realizado el año 2009 para el Instituto de Investigación Científica de la Universidad de Lima (IDIC) señalamos las coincidencias entre este síndrome y los trastornos limítrofe y narcisista de personalidad (American Psychiatric Association, 2004) y destacamos que Kiley $(1983,1984)$ hace una minuciosa descripción del síndrome junto a la cual presenta una explicación superficial. Las causas, efectivamente, resultan inciertas. La escasa literatura 
existente afirma de manera generalizada que es la sobreprotección de los padres la causa principal del síndrome, ya que a partir de ella se idealizará la juventud o adolescencia tendiendo a querer mantener su estado de privilegio. Kiley (1983), por su parte, enfatiza la falta de comunicación entre los padres, donde la madre se presenta como una mártir dedicada a atender a un hombre chauvinista y distante. Estas son, en nuestro parecer, explicaciones válidas pero insuficientes, y mantenemos la creencia de que ningún complejo puede ser verdaderamente superado sin acceder a sus raíces. En el mencionado estudio realizado para el IDIC, recurrimos a las expresiones artísticas para acercarnos a los temas que subyacen a la formación del hoy llamado síndrome de Peter Pan. Desde una perspectiva psicoanalítica, analizamos la novela original de Barrie así como algunas realizaciones cinematográficas dado que el personaje de Peter Pan ha fascinado a cineastas a lo largo de los años y en diferentes lugares del mundo. En el presente trabajo compartimos el análisis de dos de estos filmes: Peter Pan (2003) y Hook (1991).

\section{Peter Pan: La no-relación sexual COMO DEFENSA ANTE LA SIMBIOSIS}

La primera película que nos ocupa es Peter Pan, producida por los Estudios Universal, Columbia Pictures y Revolution Studios, dirigida por P. J. Hogan y en cuyo elenco se cuentan Jason Isaacs como Garfio y Jeremy
Sumpter como Peter. Se trata de una versión basada en la novela de Barrie, escrita por Michael Goldenberg, y que nos sugiere como tema central el miedo a crecer ante el conflicto edípico observado por Freud y su elaboración lacaniana en cuanto a la no-relación sexual. El conflicto de rol sexual, nos propondrá este filme, es una defensa donde se toma el imperativo social de masculinidad como excusa para escapar de la sexualidad adulta y evitar relacionarse profundamente. La trampa consecuente es elegir, como decía Bryce Echenique, entre el amor y la soledad.

Empecemos por los créditos, donde se reproduce el logo del cuento de Peter Pan, el cual incluye el diseño de la $P$ de Peter culminando en una daga hacia abajo, símbolo fálico de poder. Esto, como veremos más adelante, nos ubica ya en el terreno de lo simbólico y del Edipo. A la vez, lo pregenital está presente al empezar la película, pues una frase extraída directamente de la novela ("Todos los niños crecen, excepto uno"), nos advierte del sentimiento de ser único que vinculamos con la fantaseada omnipotencia de la infancia temprana, dejando en claro el narcisismo y el sentido de autoimportancia de Peter a lo largo de todo el filme.

Cuando vemos a Wendy por primera vez, pensamos en el conflicto de rol sexual del que habla Kiley (1983). Encontramos a Wendy contando un cuento a sus hermanos, disfrazada con una armadura, elemento masculino. Esto nos 
advierte desde el inicio que se toma en cuenta el Edipo en sus versiones tanto positivas como negativas, las cuales se integrarán después, en el mejor de los casos, para formar una identidad genérica realista (Freud, 1972a; 1972b). Los piratas del cuento de Wendy le dicen a Cenicienta ${ }^{1}$ que han venido por sus zapatos de cristal (los zapatos como fetiche nos ubican nuevamente en lo pregenital) y hacen sorna de ella por ser mujer, lo cual la irrita. En términos identificatorios, el cuento que relata es una extraña combinación de historias atractivas tanto para las niñas como para los niños. Cenicienta deja todas las cosas comunes de la vida ordinaria que lleva y se alista para ir al baile, pero se encuentra rodeada de piratas, cada cual más temible que el otro. El más terrible, por supuesto, será Garfio, "capaz de abrir un vientre en dos" (ataque al poder reproductivo de la mujer). Todos los personajes de su cuento serán luego encontrados en la realidad del país de Nunca Jamás, un país ficticio que mejor podríamos llamar una realidad psíquica, en tanto lo que presenciaremos allí es una realidad determinante pero que a la vez puede no coincidir con lo que

$1 \quad$ Kiley $(1983,1984)$ afirma que la versión femenina del síndrome de Peter Pan es la Cenicienta, una mujer que busca depender de un hombre a quien idealiza y ser protegida por él, sin deseos de crecimiento personal. Entonces, esta película ubica a Wendy en el mismo complejo que a Peter. entendemos como realidad exterior y objetiva.

Wendy sabe que el beso que su madre conserva en la esquina derecha de su boca nunca será para ella. Ella la mira con admiración y tristeza a la vez, resentida por lo que podemos suponer es su reconocimiento de no ser objeto de deseo materno. La familia de Wendy conversa sobre el futuro (luego nos enteraremos que lo mismo sucedió con Peter poco antes de que escapara de su hogar) y se concluye que Wendy se está convirtiendo en mujer. El rechazo de la madre y su negación del beso que pende de su boca se vincula directamente con el siguiente paso en el desarrollo, el volverse la niña hacia el padre como figura deseada (Freud, 1972b). No el padre real, sino un hombre imaginario aún por llegar, que tendrá el cielo cuando posea el beso que Wendy, al igual que su madre, guarda. Se trata de la más grande aventura de todas. "Más allá de la vida y la muerte", como dice Peter, "el amor es lo más complicado".

Dado que la madre de Wendy no le entrega su beso a su esposo, podría suponerse un rechazo o devaluación de su pareja. Sin embargo, la vemos enamorada en tanto respeta los esfuerzos y sacrificios de su marido, y les dice a sus hijos que se requiere mucha valentía para renunciar a los sueños por los hijos. Los sueños están guardados en un cajón y cada noche los sacan para admirarlos, y cada vez es más difícil volverlos a en- 
cerrar, pero el padre lo hace. La madre es escuchada con atención, se ha vuelto a convertir en un objeto importante, ya no de deseo (Lacan, 1971a) sino en un modelo de identificación. Ella presenta en su relato un hombre real al que admirar. Sin embargo, deberá acompañarlo a una reunión importante porque, a pesar de ser valiente, tal vez necesite el beso esa noche.

Parece leerse en esta película que el poder viene de la mujer. Ella debe investir al hombre para que este se valore y tenga energía. Hacia el final de la película, Wendy también salvará a Peter, deprimido y desenergizado, tomado por el instinto de muerte, con un beso. Se voltea así en este filme la perspectiva de las historias de amor, donde Blancanieves y la Bella Durmiente son más bien ellas salvadas por el beso. En todo caso, parecería que es la integración de los diferentes, masculino y femenino, lo que hace que uno se salve del instinto de muerte, que divide y desenergiza. En su primer encuentro Peter le dice a Wendy "Una niña vale más que 20 niños", "Los niños que caen de la cuna cuando las nanas no están mirando... las niñas son demasiado inteligentes para caerse de la cama". La lucha genérica aparece en diversos comentarios y se evidencia el conflicto del varón entre sus fuertes sentimientos idealizantes hacia su madre, por un lado, y por otro sus impulsos de diferenciación, que lo llevan a rechazar lo femenino (y por ende las demostraciones afectivas de la madre) para no ser tratado socialmente como una niña (Chodorow, 1978).

Peter ha llegado hasta la cama de Wendy en la última noche de su infancia, e intenta tocarle la boca, con curiosidad, como si hubiera atisbado el beso que se le empezaba a dibujar ahí. Una toma nos muestra el rostro sorprendido de Wendy enmarcado en sus sábanas haciéndola parecer una virgen. Cuando ella despierta él escapa, pero deberá volver a recoger su sombra, aquella que Wendy coserá reintegrándosela a Peter. Se nos muestra, a la vez, la represión social de la sexualidad, tanto en tías como en maestras, que se horrorizan ante los dibujos que Wendy hace de Peter mientras sueña despierta. El tiempo se detiene en los relojes cuando llega Peter, como si se nos dijera que justo antes de un hito en el desarrollo, hay un momento de parálisis, o de reediciones de lo anterior. Al final de la película, Wendy cambia el cuento de Cenicienta porque ya no es una niña, ahora es una muchacha con una cierta madurez que le permite hacerse cargo, en gran medida, de su propia historia.

Las miradas de fascinación abundan a lo largo de toda la película entre Wendy y Peter. Encontramos el elemento voyerista, que nos ubica una vez más en lo pregenital. Peter ha visitado a Wendy en otras ocasiones, solo para escuchar sus cuentos en secreto. Sus ojos, curiosos, observando a Wendy, son explotados en innumerables close-up. Las alusiones a la curiosidad sexual están 
ubicadas en constantes miradas de descubrimiento del otro diferente, miradas en ocasiones enmarcadas en símbolos como corazones que son parte del adorno de los muebles. Mientras le cuenta a Wendy cómo huyó cuando oyó a sus padres hablar de lo que sería de grande, ella está explorando a los personajes de su casita de muñecas, acto que indica que lo que rechazó conflictuado era su rol masculino como futuro padre, o tal vez la sexualidad en sí, remarcado esto por una mirada más.

El despertar a la sexualidad está adicionalmente remarcado en la interpretación de los actores y claramente en la elección del casting, pero también en el hecho de que el despliegue emocional de la pubertad se produce particularmente en la noche, y Wendy pasa toda la película en su ropa de dormir para recordarnos esto. El personaje de Peter, sin embargo, resulta bastante ingenuo en el campo de la sexualidad. A pesar de ser sumamente seductor, niega totalmente las aproximaciones sexuales de Tigrilla, de Wendy y de la propia Campanita.

Desviémonos por un momento del idilio entre Peter y Wendy. Efectivamente, Peter no viaja solo. Lo hace con Campanita, su hada, descrita en la novela original como "una niña con una figura exquisitamente explotada por su vestido de hojas, el cual destaca sus formas redondeadas". Se trataría, pues, de una figura materna con connotaciones edípicas. Igual que la madre escindida percibida por un niño pequeño, las hadas son tan pequeñas que solo pueden tener un sentimiento a la vez. Les está permitido cambiar, no obstante, pero siempre que se trate de un cambio completo. Son leales y protectoras, pero se enfurecen de maneras mortales (suministros de amor y protección para sobrevivir psíquicamente). Las hadas no hablan -madre de la etapa preverbal-, y tienen magia -madre omnipotente preedípica-. Las hadas pueden ser también entendidas como el bebé, que aún no integra, o como la madre identificada con ese bebé. Las hadas, pues, nos remontan a las madres de la primera etapa, omnipotentes y capaces de crear la ilusión (Winnicott, 1992). También amenazadoras si llegan a molestare.

Esa madre, como las hadas, no puede morir; y sin embargo, es necesario matarla simbólicamente cuando dejamos de creer en su omnipotencia. Por otro lado, las hadas, nos dice Barrie en su novela, son creadas por los niños. Cuando el primer niño rio por primera vez "su risa se rompió en mil pedazos que saltaron por los aires y ese fue el principio de las hadas".

Peter ha llegado a pensar que las madres son sobrevaloradas y esto le da pena: "Las madres siempre están dispuestas a ser usadas como parachoques. Todos los niños lo saben y desprecian a las madres por ello, pero lo utilizan a todas horas". Si Peter había tenido madre alguna vez ya no la echaba de menos, "era algo de lo que podía prescindir 
perfectamente". Evitaba reencontrarla, pues, en clara proyección de sus "culpas", temía que al verlo dijera que era muy mayor. Nos remite esto al temido resentimiento de las madres ante el crecimiento de sus hijos y eventual distanciamiento del vínculo materno a partir del ejercicio de la autonomía.

Volviendo a Peter y Wendy, en una de las visitas clandestinas de este a la casa de los Darling (nótese que el ape1lido elegido para esta familia significa en castellano "querido"), convence a Wendy de irse con él. A través de un viaje galáctico con alusiones a lo intrauterino, llegan a Nunca Jamás, donde las sirenas son criaturas oscuras, en contacto con todas las cosas misteriosas, como la madre mujer que conoce los misterios de la sexualidad, la concepción y el alumbramiento. Por su lado, los piratas son pecadores y viciosos y disparan cañones, otro símbolo fálico.

Una vez en Nunca Jamás, Peter seguirá observando, esta vez a las hadas, e invitará a Wendy a presenciar un baile de bodas entre estas criaturas. Ellos mismos se ponen a bailar románticamente, imitando a los novios. Cuando están a punto de besarse Peter se detiene y le aclara que es solo una fantasía. Es evidente que él quiere quedarse en el juego de roles, en el "como si"; es ella quien trata de convencerlo de que puede ser real: la madre edípica percibida como engolfante, aunque no lo sea. El terror al incesto. El problema de crecer, para Peter, es que "aparecen granos", pero también deseos y sentimientos para los que no se siente listo. El mundo de las mujeres es amenazante, demasiado complejo para ser entendido aún. A pesar de su respeto por algo que no puede abarcar, lo devalúa y afirma abiertamente que nunca se enamorará porque eso es "cosa de niñas".

En Nunca Jamás encontramos, adicionalmente, a un Garfio representado por el mismo actor que interpreta al padre de Wendy, con una personalidad totalmente opuesta. Mientras el padre de Wendy es en la novela original inmaduro, pataletudo, infantil y caprichoso, incapaz como padre, en este filme es apocado y tímido, y aunque poco exitoso, lucha por sacar adelante a sus hijos a pesar de sus deficiencias personales, entre ellas una abrumadora inseguridad respecto a cómo lo validan sus jefes. Sabe, por necesidad, el precio de todo, hasta de un abrazo, aunque no trastoca sus valores. Garfio, en cambio, es presentado como un astuto galán y como enemigo, una verdadera amenaza que no se puede subestimar. Tiene unos ojos seductores "tan azules como el olvido", que se tornan rojos cuando enfurece. Estos ojos no asustaron a Wendy, más bien la embelesaron. Eventualmente, será seducida por él.

A pesar de que Peter devalúa a Garfio, y es precisamente en quien no se quiere convertir, el vínculo de identidad se hace evidente cuando imita su voz para confundir a sus secuaces. En la película se nos cuenta que los niños 
que tienen padres malos sufren por ser sus hijos y no quieren crecer para no ser como ellos. Es, entonces, en este juego de proyecciones e introyecciones que el niño se pelea con el adulto que empieza a reconocer en su mundo interior.

Peter no puede amar-igual que en el síndrome-pero curiosamente, esta es una de las características que lo hacen seductor, tanto como enigmático. Wendy se identifica con Garfio para comprender a los hombres. Y se convierte en la temible Red Handed Jill, rival de Peter, madre fálica peligrosa convertida en pirata. Wendy se molesta cuando Peter la "devalúa" volviéndola a convertir en "contadora de cuentos", y está dispuesta a mostrar su lado masculino, aquel que la ubica como un glorioso espadachín.

Wendy quiere herir a Peter por su rechazo y lo hace diciéndole que no es eficiente porque es "solo un niño". Está segura de que su deseo de ser por siempre niño es su mayor pretensión. Para ella es claro que no se atreve a crecer para no tener que competir en el terreno de Garfio, el de la verdadera seducción, aquel para el cual aún no está equipado. Garfio coincide en esto al decirle que Wendy lo prefiere a él porque ya es un hombre, y que en el futuro ella tendrá un esposo que lo reemplazará en sus afectos. Estas afirmaciones son devastadoras para Peter quien, adicionalmente, se siente más vulnerable ahora que tiene sentimientos hacia Wendy. Sus sentimientos lo paralizan: cuando ella está a punto de ser lanzada al mar por Garfio, el dolor de perderla le impide volar para salvarla. Al final Wendy le otorga su beso oculto, con el que lo revitaliza y le devuelve su poder. Sin embargo, la tragedia de Peter es haber descubierto sus sentimientos, con lo que debe abandonar por completo la omnipotencia previa, reconocerse incompleto y necesitado. O permanecer solo y sin amor, jugando a estar acompañado, pero siempre con una mano en la ventana para salir volando.

\section{HOOK: EL IMPERATIVO DEL TIEMPO}

En esta película, dirigida por Steven Spielberg en 1991, protagonizada por Robin Williams, Dustin Hoffman y Maggie Smith, Peter Pan finalmente ha crecido y se ha enamorado para encontrar, sin embargo, una vida muy poco satisfactoria. Atrapado en la rutina y el trabajo, es un empresario pirata, que lucra de los botines que obtiene al fusionar empresas que van a quebrar, y que no se da tiempo para las cosas importantes, como su familia.

Lo que de esta película se puede extraer como introspección es que lo que detiene el crecimiento real, el del corazón, es el miedo a la impulsividad desenfrenada, a lo salvaje y no domesticable, a aquello que se puede descontrolar si no se le ponen límites rígidos. Tan rígidos, que Peter termina temiendo a todo aquello de lo que antes disfrutaba: las ventanas abiertas, los aviones, volar, 
jugar. Pero sobre todo, cuando viaja en avión, teme ser tragado y morir aturdido por la energía interior. Sus defensas son tan rígidas que lo paralizan y le impiden disfrutar de nada.

Los impulsos están presentes, a lo largo de toda la película, en las sombras: la sombra del pasado, la sombra del hijo que mientras juega se proyecta, gigante, sobre la pared del cuarto, sombras de juguetes en los techos y las paredes altas. Un mundo paralelo de sombras. Escuchamos a un Peter nostálgico recordar que alguna vez persiguió su sombra en casa de Wendy; pero sabemos que Peter ya no es "ni la sombra" del Pan que alguna vez fue. Durante el filme, cuando está perdido, su sombra es oscura, pero se torna blanca si empieza a reconectarse con su mundo impulsivo e infantil, o cuando se atreve a luchar y a hacer frente a las dificultades. Las sombras pelean entre sí, representando los conflictos inconscientes, y la mayoría de veces no están detrás, sino que preceden a los personajes, como un camino inevitable a seguir. Finalmente, su reflejo en el estanque, narcisismo disociado y ahogado adrede, se libera y lo obliga a seguirlo.

A lo largo del filme nos enteramos de que Wendy amó a Peter hasta el día de su boda, cuando finalmente decide crecer. Peter siguió visitándola y se enamoró eventualmente de Moira, su nieta de 13 años, decidiendo también por fin crecer. Wendy se convierte en la abuela adoptiva de Peter, a la que cada vez vi- sita menos. La película se inicia cuando Moira, su esposa, le pide ir a Londres a visitar a la abuela Wendy. Su esperanza es que pueda él desconectarse de sus abrumadoras ocupaciones y comparta algo de tiempo en familia. No deja de recordarle que sus hijos lo aman, y que su infancia y su adoración no durarán para siempre. Es pues, esto, lo que el tiempo trae, el olvido de nuestras imágenes infantiles.

Garfio aprovecha la visita para secuestrar a los hijos de Peter y obligarlo a regresar a Nunca Jamás en su rescate, conminándolo al duelo que le debe. Peter no entiende, porque no recuerda su vida pasada, pero este olvido lo ha dejado con un sentimiento de vacío. Hay que recordar para poder elaborar. Entrampado en repeticiones (la historia se repite, cada año, en la obra Peter Pan que se representa en el colegio de sus hijos) va perdiendo una y otra vez su oportunidad de elaborar el pasado. Cuando llega a Nunca Jamás, encuentra a otro Peter. Un chico en skate que nos recuerda la marginalidad del dios Pan, un muchacho que debe haber buscado desesperadamente pertenecer y ser aceptado, para terminar escapando a un lugar en donde finalmente se le ha otorgado la espada de Peter y su autoridad.

En este filme Garfio es presentado como un niño grande, infantil e inmaduro, el niño que se odia a sí mismo por ser malo, por robar tiempo y energía a sus padres, y convierte esta profecía en robar botines. Odia a Peter Pan aunque 
se parece mucho a él y considera que su mayor venganza sería enamorar a los hijos de Peter; tiene impulsos suicidas y de autodestrucción, y aunque reales, los usa para manipular. Tomado por una gran depresión y sentimientos de vacío, entrampado en un narcisismo que le obliga a rodear su cama de espejos, reconoce las grietas de estos cuando confiesa que todas las partes inconclusas de su vida se juntaron, y en lo que él llama una epifanía, comprende que su vida se acabó.

Es la vejez y la muerte lo que acecha, pues todo aquel que crece tiene que morir. Atreverse a crecer, y a morir eventualmente, sería la mayor aventura de todas. Es por esto que si bien la frase "morir sería una gran aventura", se repite en la película, también aparece la de "vivir sería una gran aventura". En una escena final, Garfio es derrotado y pierde en la batalla su peluca, otro símbolo fálico de poder y dignidad. Humillado, ruega que le permitan volver a colocársela. Es esta belleza y juventud la que se ha esmerado en conservar, escapando del tiempo que lo persigue en el cocodrilo que se tragó su reloj; escapando de asumir las separaciones, la pérdida de la juventud, la pérdida de la fusión con la madre.

El propósito de este trabajo ha sido ampliar las explicaciones ofrecidas por el doctor Kiley, al considerar que arma un rompecabezas complejo y coherente, pero superficial. Hemos intentado, en ese sentido, ofrecer interpretaciones, a través de las propuestas de dos filmes relacionados con el tema, que se aventuren en un terreno más inconsciente. A partir del material analizado aparecen algunos otros insights interesantes.

El primero y más saltante se ubica en relación con el conflicto de rol sexual que propone Kiley (1983, 1984). Si bien él ve este problema como uno meramente social, en tanto hombres y mujeres son moldeados con diferentes imperativos de crianza, los filmes ponen de manifiesto algo más vinculado a la naturaleza inconsciente de lo femenino y lo masculino, una no-complementariedad psíquica de los sexos en el sentido lacaniano (Lacan, 1972a; 1972b). La pregunta lacaniana de "¿Qué quiere la mujer?" aparece vigente en las películas revisadas, aunque sugiriendo respuestas teñidas por constructos sociales. Lo saltante aquí es que cualquier Peter Pan asumirá que el deseo último de la mujer es divergente de aquel del hombre, y por lo tanto la satisfacción plena en una pareja es imposible. Engranándose esto en las explicaciones ofrecidas por Kiley (1983), sin embargo, podemos agregar que los mensajes paternos chauvinistas colocan a la mujer en un lugar de simpleza psíquica que acentúa el abismo para llegar a comprenderla. La víctima del síndrome de Peter Pan, identificada con este padre incapaz de comprender a su mujer, y con poca voluntad para intentarlo, enfrentará las relaciones de pareja con pocos recursos y menores oportunidades de éxito, y se colocará 
en una necesidad de confirmar que conserva el control.

Por otro lado, los propios impulsos sexuales, dependientes en parte de lo constitucional, pero exacerbados en la pubertad, acrecentarán el temor al descontrol. En los filmes la irrupción de la sexualidad es llamativa, pero a la vez reprimida, rechazada, y en algunos casos escondida y condenada. La vinculación entre pareja y figura materna hace que la culpa sea mayor. Los filmes sugieren que, en este sentido, el Peter Pan moderno se queda entrampado en una posición de voyeur, desde la cual puede mantener el control y pretender no estar involucrado.

En relación con lo anterior podemos engranar también lo que Kiley (1983) llama "complejo materno": una rabia convertida en ambivalencia hacia la madre, una imposibilidad de alejarse de ella. Lo que los filmes aportan en la comprensión de este complejo es una visión más profunda de esta ambivalencia, la cual tiene que ver con el abandono de la omnipotencia que vive el infante cuando goza, en los primeros meses de su vida, de una identificación plena con su madre. Una madre a la que percibe omnipotente también, respecto a quien aún no puede experimentarse como separado. La renuncia a esta identificación, y por lo tanto el reconocimiento de la propia incompletud y necesidad, dejan al infante sintiéndose vulnerable. El temor generado por este descubrimiento se convierte reactivamente en desprecio y luego será proyectado a la madre con la sensación de ser rechazado por ella. Esta sería la base de la rabia y el reproche, la cual posteriormente, por supuesto, podrá consolidarse y agravarse en cada momento del desarrollo en el cual el niño deba ejercer su autonomía, sobre todo si la madre real se muestra efectivamente rechazante.

Si bien es cierto que quien sufre el síndrome de Peter Pan intentará manipular a la madre, y a cualquier mujer que eventualmente la represente, a través de la pena, esto también implica un reconocimiento velado de la propia autocompasión, residuo de la vulnerabilidad sentida. Queda claro, entonces, que la madre que se reedita en la pareja de alguien que sufra el síndrome de Peter Pan ostenta una combinación de elementos edípicos y preedípicos, pero se trata, sobre todo, de la madre de la identificación original. Aquella que representó en su momento a todo el entorno, aquella a la que debemos renunciar para ser individuos singulares; aquella que podría engullir nuestra identidad si la separación fuera obstaculizada.

Adicionalmente, el eventual rechazo materno, podrá surgir de las propias identificaciones y apegos de la figura materna. Hemos discutido cómo el crecimiento de un niño genera inseguridades en su madre. Ella, regresionada en identificación con su propio bebé, revivirá durante la infancia temprana de este, y de manera inconsciente, sus 
propios conflictos pasados con su madre (Raphael-Leff, 1995). Así, el crecimiento de su hijo movilizará también sus sentimientos de vulnerabilidad $y$ sus apegos no resueltos, reeditará su propia omnipotencia para luego obligarla a volver a reconocer su incompletud. En nuestra opinión, es en este sentido que los filmes aluden a la transmisión intergeneracional de los conflictos del apego, los cuales se reeditan en una historia después de otra. La pérdida de memoria, por su parte, es una contribución a estas repeticiones. Cualquier terapeuta psicoanalítico sabe bien que, para romper el círculo repetitivo del instinto de muerte que impide el desarrollo, es necesario recordar y elaborar.

La separación-individuación, vivida inconscientemente como una pérdida necesaria (Viorst, 1986) pero dolorosa, será asumida como un duelo natural en el desarrollo. Sin embargo, las complicaciones que pudieran agregarse expondrán al sujeto a mayores dificultades para posteriores pérdidas y duelos. Reactivamente, se desinvestirá de afectos a las figuras más significativas para protegerse del eventual y posible dolor de perderlas. Podemos asociar a esto el aparente desinterés en los otros del que Kiley (1984) habla. El sujeto, expuesto así a pérdidas abrumadoras, se verá en la disyuntiva entre crecer de golpe -para lo cual no siempre estará listo- o detener su desarrollo en un momento previo al dolor.
Tenemos, entonces, que el deseo de no crecer que caracteriza al Peter Pan de Kiley tiene que ver con la búsqueda de la eterna juventud y la evasión de las responsabilidades, la persecución del goce constante. Pero el miedo a crecer, aquel del que nos hablan los filmes, sería sinónimo, en términos generales, del miedo a la sexualidad y del miedo a la muerte. El miedo a perder la completud original o el miedo a conservarla para siempre y no llegar a existir como sujetos; el miedo a destruir a la madre o a ser destruido por ella. En este sentido, más que evocar el narcisismo de Kiley, planteamos la omnipotencia primaria. Finalmente, si bien Kiley (1983) ofrece una explicación que centra los orígenes del síndrome en la crianza, consideramos que los factores de intensidad constitucional (Kernberg, 1979; 1991) deberían tomarse en cuenta en posteriores investigaciones.

\section{REFERENCIAS}

American Psychiatric Association (2004). Diagnostic and statistical manual of mental disorders, DSM$I V$. Washington D.C.: American Psychiatric Association (APA).

Barrie, J. M. (2006). Peter Pan. Madrid: Santillana.

Chodorow, N. (1978). The reproduction of mothering. Berkeley: University of California Press. 
Freud, S. (1972a). La organización genital infantil. En Freud, S. Obras completas. Tomo VII. Madrid: Biblioteca Nueva.

Freud, S. (1972b). La disolución del complejo de Edipo. En Freud, S. Obras completas. Tomo VII. Madrid: Biblioteca Nueva.

Kernberg, O. (1979). Desórdenes fronterizos y narcisismo patológico. Buenos Aires:Paidós.

Kernberg, O. (1991). La teoría de las relaciones objetales y el psicoanálisis clínico. México D. F.: Paidós.

Kiley, D. (1983). The Peter Pan syndrome: Men who never grow up. Nueva York: Mead.
Kiley, D. (1984). The Wendy dilemma. When women stop mothering their men. Nueva York: Avon.

Lacan, J. (1971a). El estadío del espejo. En Escritos I (pp. 5-35). Buenos Aires: Siglo XXI.

Lacan, J. (1972b). Los tres tiempos del Edipo. En Seminario V (pp. 293343). Buenos Aires: Paidós.

Raphael-Leff, J. (1995). Pregnancy, the inside story. New Jersey: Jason Aronson Inc.

Viorst, J. (1986). Necessary losses. Nueva York: Ballantine Books.

Winnicott, D. (1992). Los procesos de maduración y el ambiente facilitador. Barcelona: Gedisa. 